\title{
Transgenesis in the parasitic nematode Strongyloides ratti
}

\author{
Xinshe $\mathrm{Li}^{\mathrm{a}}$, Hongguang Shao ${ }^{\mathrm{a}}$, Ariel Junio ${ }^{\mathrm{a}}$, Thomas J. Nolan ${ }^{\mathrm{a}}$, Holman C. Massey Jr. ${ }^{\mathrm{a}}$, \\ Edward J. Pearce $^{\mathrm{c}}$, Mark E. Viney ${ }^{\mathrm{b}}$, James B. Lok ${ }^{\mathrm{a}, *}$
}

a Department of Pathobiology, School of Veterinary Medicine, University of Pennsylvania, 3800 Spruce Street, Philadelphia, PA 19104, USA

${ }^{\mathrm{b}}$ School of Biological Sciences, University of Bristol, Woodland Road, Bristol BS8 1UG, UK

${ }^{\mathrm{c}}$ Trudeau Institute, Saranac Lake, NY, USA

\section{A R T I C L E I N F O}

\section{Article history:}

Received 12 May 2011

Received in revised form 13 June 2011

Accepted 15 June 2011

Available online 23 June 2011

\section{Keywords:}

Transgenesis

Strongyloides ratti

Parasitic nematode

Microinjection

Plasmid vector

\begin{abstract}
A B S T R A C T
Strongyloides and related genera are advantageous subjects for transgenesis in parasitic nematodes primarily by gonadal microinjection as has been used with Caenorhabditis elegans. Transgenesis has been achieved in Strongyloides stercoralis and in Parastrongyloides trichosuri, but both of these lack welladapted, conventional laboratory hosts in which to derive transgenic lines. By contrast, Strongyloides ratti develops in laboratory rats with high efficiency and offers the added advantages of robust genomic and transcriptomic databases and substantial volumes of genetic, developmental and immunological data. Therefore, we evaluated methodology for transgenesis in S. stercoralis as a means of transforming $S$. ratti. S. stercoralis-based GFP reporter constructs were expressed in a proportion of F1 transgenic S. ratti following gonadal microinjection into parental free-living females. Frequencies of transgene expression in S. ratti, ranged from $3.7 \%$ for pAJ09 to $6.8 \%$ for pAJ20; respective frequencies for these constructs in $S$. stercoralis were $5.6 \%$ and $33.5 \%$. Anatomical patterns of transgene expression were virtually identical in S. ratti and S. stercoralis. This is the first report of transgenesis in S. ratti, an important model organism for biological investigations of parasitic nematodes. Availability of the rat as a well-adapted laboratory host will facilitate derivation of transgenic lines of this parasite.
\end{abstract}

(c) 2011 Elsevier B.V. All rights reserved.
Although stable transgenesis in Caenorhabditis elegans was achieved almost two decades ago [1-3], adaptation of this now standard method to animal parasitic nematodes has been difficult and relatively slow. Difficulties in accomplishing this stem mainly from the fact that most medically important parasitic nematodes are obligate parasites and cannot be cultured for a full generation outside their hosts. By contrast, members of the superfamily Strongyloidoidea, which resides in Clade IV of the contemporary nematode phylogeny [4,5], naturally undergo one or more generations of free-living adult development between parasitic generations [6]. The culture biologies and body plans of the freeliving females of Strongyloides spp. and Parastrongyloides spp. are so similar to those of $C$. elegans hermaphrodites that it has been relatively straightforward to adapt the technique of gene transfer by gonadal microinjection to this group of parasitic nematodes. Consequently, heritable transgenesis using this method has been achieved for Strongyloides stercoralis [7-9] and Parastrongyloides trichosuri $[10,11]$.

\footnotetext{
* Corresponding author. Tel.: +1 215898 7892; fax: +1 2155737023

E-mail address: jlok@vet.upenn.edu (J.B. Lok).
}

As research subjects, both of these parasites have distinct advantages, but also some disadvantages. P. trichosuri is the more genetically tractable of the 2 parasites. It can undergo repeated generations of free-living development under appropriate environmental conditions that may be simulated on laboratory culture plates [10]. This factor has allowed derivation of stable transgenic lines by culture passage in a manner similar to protocols for C. elegans [11]. Offsetting this advantage is the fact that $P$. trichosuri is a natural parasite of the Australian brush-tailed possum, Trichosurus vulpecula, an animal that is very difficult to obtain and maintain in the laboratory. Efforts to introduce $P$. trichosuri into more widely available non-marsupial species have failed thus far, but a smaller Australian marsupial, the sugar glider, Petaurus breviceps, is susceptible to infection and has proven a practical laboratory host for this parasite [12]. The sugar glider is commercially available through the pet trade in many parts of the world, but it is not, to our knowledge, bred for research, and so its use as a laboratory animal may be problematic in some settings.

As a parasite of humans, $S$. stercoralis is the most medically significant member of the Strongyloidoidea. It infects approximately 300 million people and, because of its unique capability to undertake autoinfection, can cause potentially fatal disseminated hyperinfection in persons immunocompromised as a result of HTLV-1 infection [13,14] or immunosuppressive drug therapy 


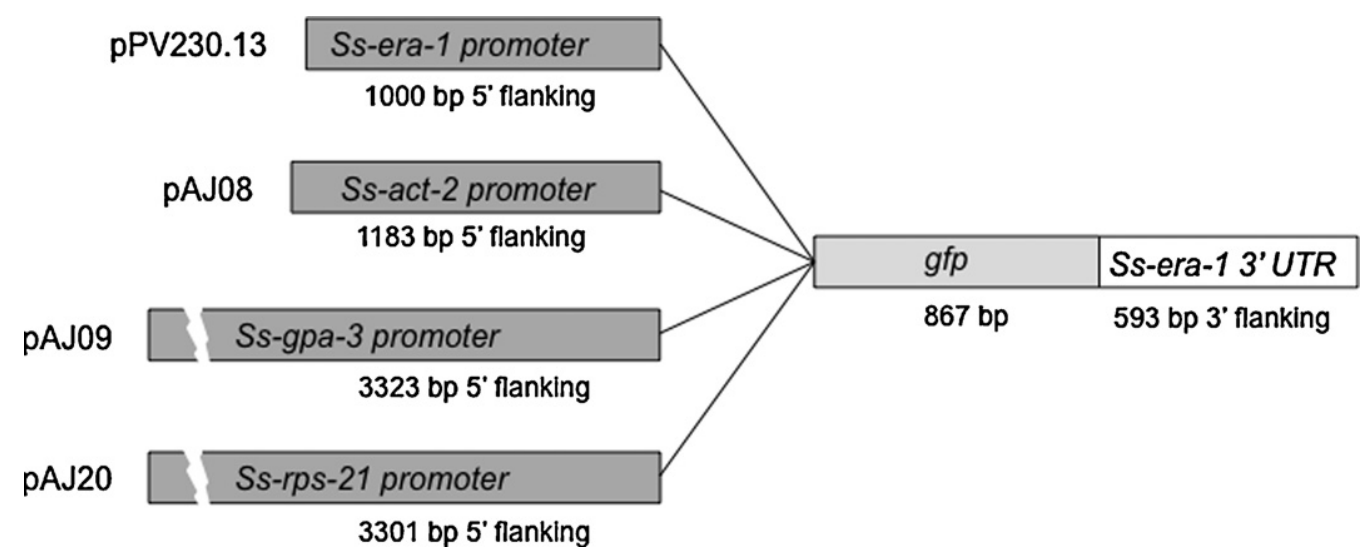

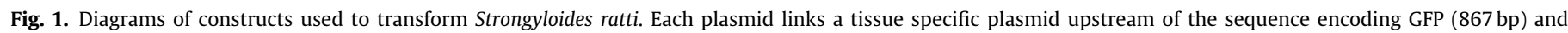

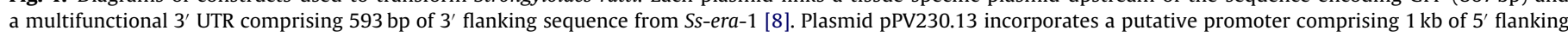

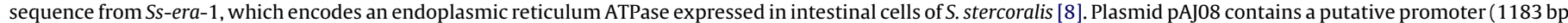

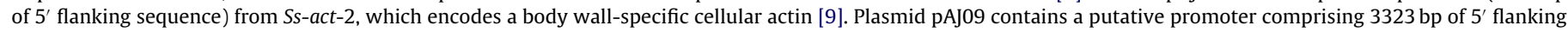

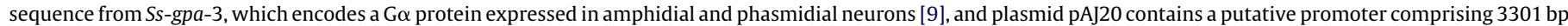

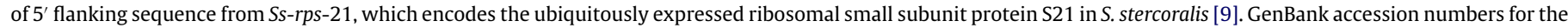

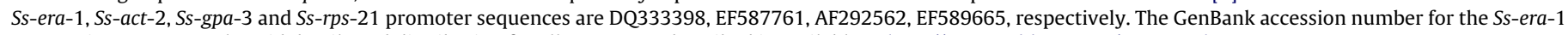
32 UTR is DQ333399. Plasmid details and distribution for all constructs described is available at http://www.addgene.org/James_Lok.

$[15,16]$. Like $P$. trichosuri, the life cycle of $S$. stercoralis contains free-living females and these provide a convenient target for gene transfer by gonadal microinjection [7]. However, S. stercoralis is capable of undergoing only one generation of free-living development, and all progeny of free-living males and females develop to infective third-stage larvae (L3i). Consequently, derivation of stable transgenic lines of $S$. stercoralis will necessitate host passage of F1 transformants. A natural parasite of humans and dogs, S. stercoralis will also establish patent infection in the Mongolian gerbil, Meriones unguiculatus [17], thus providing a small animal system for host passage. The infection efficiency of S. stercoralis in the gerbil is such that on average $6.5 \%$ (range $=0.6-27.6 \%$; $n=540$ ) of inoculated infective third-stage larvae (L3i) establish as adult parasitic females in the gerbil $[9,17]$. The frequency of germline transformation resulting from gonadal microinjection of DNA into parental free-living females in S. stercoralis has not yet been determined, but the corresponding value for $\mathrm{F} 1$ progeny of microinjected C. elegans hermaphrodites rarely exceeds $10 \%$ [18]. If it is assumed that this transformation frequency also applies to S. stercoralis (though this has not yet been determined), this means that derivation of a single germline transformed parasitic female S. stercoralis would require inoculation of 167 transgenic L3i into a gerbil. Although possible, such numbers are challenging to produce with current microinjection technology; the requisite number of 167 L3i for a single germline transformant would entail microinjection of 60 P0 free-living females in the S. stercoralis system. It is clear then that a more efficient host-parasite system is required for practical, routine generation of stable transgenic lines of Strongyloides spp.

Strongyloides ratti is a natural parasite of the rat and has been used as a subject for studies into a wide range of topics including host-parasite relationships [19], genetic determinants of developmental fate [19-21], ageing [22,23], the genetics of anthelmintic resistance [24], and global patterns of gene expression that differentiate parasitic from free-living nematodes [25,26]. The availability of a well-adapted conventional laboratory animal host, the rat, has greatly facilitated many of these studies. In contrast to the relative inefficiency of the S. stercoralis-gerbil system, the rat allows from $50 \%$ to $100 \%$ of inoculated S. ratti L3i to develop to reproductively active parasitic females in a period of about five days, compared to a prepatent period of 10 days, with 21 days until peak adult worm establishment, for $S$. stercoralis in the gerbil $[27,28]$. This represents an infection efficiency that is 8 - to 15 -fold higher than is seen for $S$. stercoralis in the gerbil $[9,17]$. We have confirmed this efficiency estimate for $S$. ratti in the course of the present study by generating patent infection in 6 rats by inoculation of 10 or fewer L3i. Indeed one patent infection followed injection of a single $S$. ratti L3i. Coupled with an estimated stable germline transformation rate of $10 \%$ (above), this infection efficiency could enable derivation of a single germline transformant F1 from inoculation of only $20 \mathrm{~S}$. ratti L3i into a rat. In addition to its other merits as an important model for parasitological research, this 8-fold higher probability of isolating stable transgenic parasites from a population of transiently transformed F1s makes $S$. ratti an attractive model for work towards a robust system for transgenesis in a parasitic nematode. To this end, we investigated whether $S$. ratti could be transformed by methods already developed for S. stercoralis.

Laboratory strains of S. stercoralis (UPD) and S. ratti (ED321) [20] were maintained and cohorts of free-living females were isolated from fecal culture $[29,30]$ and microinjected intragonadally with plasmid vectors as described previously [7-9] with the exception that as a precaution against its lower tolerance for injection trauma,

Table 1

Expression frequencies of Strongyloides stercoralis-based reporter constructs in F1 transgenic S. ratti and S. stercoralis.

\begin{tabular}{|c|c|c|c|c|}
\hline Construct & Parasite & No. P0 females microinjected & No. F1 progeny screened & No. (\%) F1 progeny expressing GFP \\
\hline \multirow[t]{2}{*}{ pAJ08 } & S. ratti & 60 & 207 & $16(7.4)$ \\
\hline & S. stercoralis & 42 & 838 & $123(14.6)$ \\
\hline \multirow[t]{2}{*}{ pPV230.13 } & S. ratti & 55 & 323 & $17(5.3)$ \\
\hline & S. stercoralis & 37 & 373 & $40(10.7)$ \\
\hline \multirow[t]{2}{*}{ pAJ20 } & S. ratti & 45 & 384 & $26(6.8)$ \\
\hline & S. stercoralis & 57 & 609 & $204(33.5)$ \\
\hline \multirow[t]{2}{*}{ pAJ09 } & S. ratti & 48 & 163 & $6(3.7)$ \\
\hline & S. stercoralis & 43 & 356 & $20(5.6)$ \\
\hline
\end{tabular}


only 1 of the 2 gonadal arms was injected in S. ratti. The plasmid vectors all encoded reporter constructs in which the sequence encoding GFP was cloned downstream of one of four putative tissue-specific promoters from S. stercoralis and upstream of the Ss- era-1 3' UTR from S. stercoralis (Fig. 1). Microinjected female worms were pooled with equal numbers of uninjected free-living males on NGM plates with lawns of Escherichia coli OP50 bacteria and incubated at $22{ }^{\circ} \mathrm{C}$. At 48 and $72 \mathrm{~h}$ following microinjection, F1 progeny
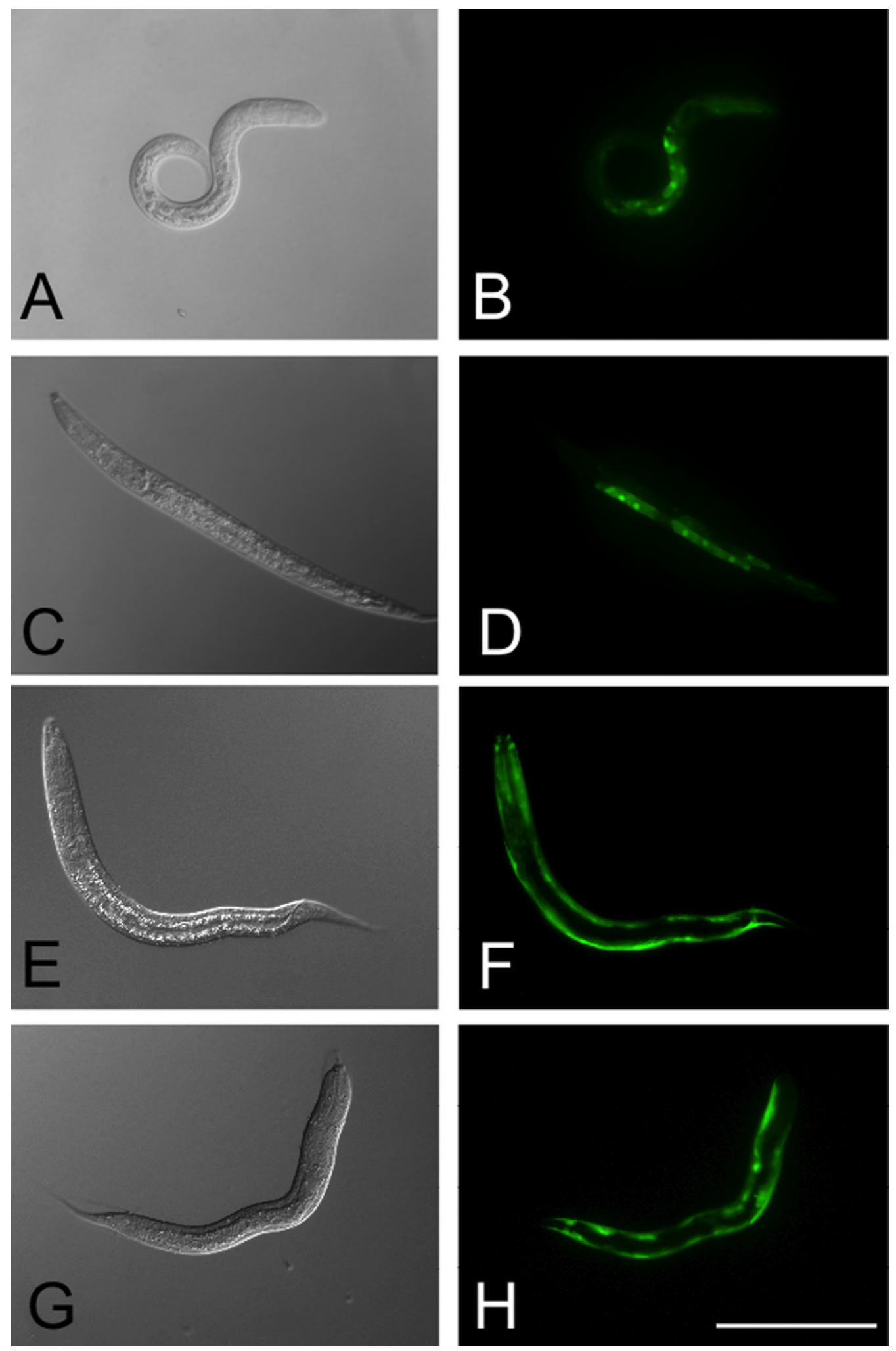

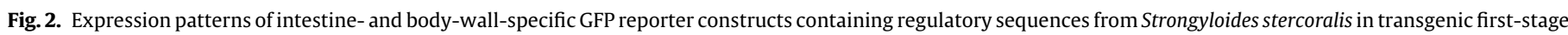

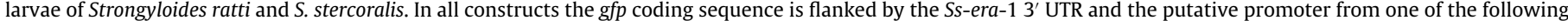

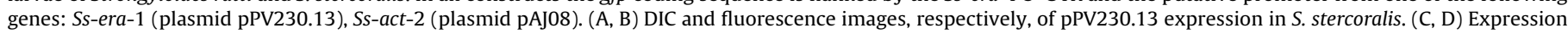

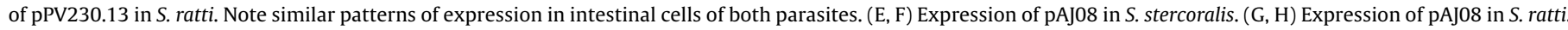
Note virtually identical patterns of expression in body walls of both parasites. Scale bar $=200 \mu \mathrm{m}$. 

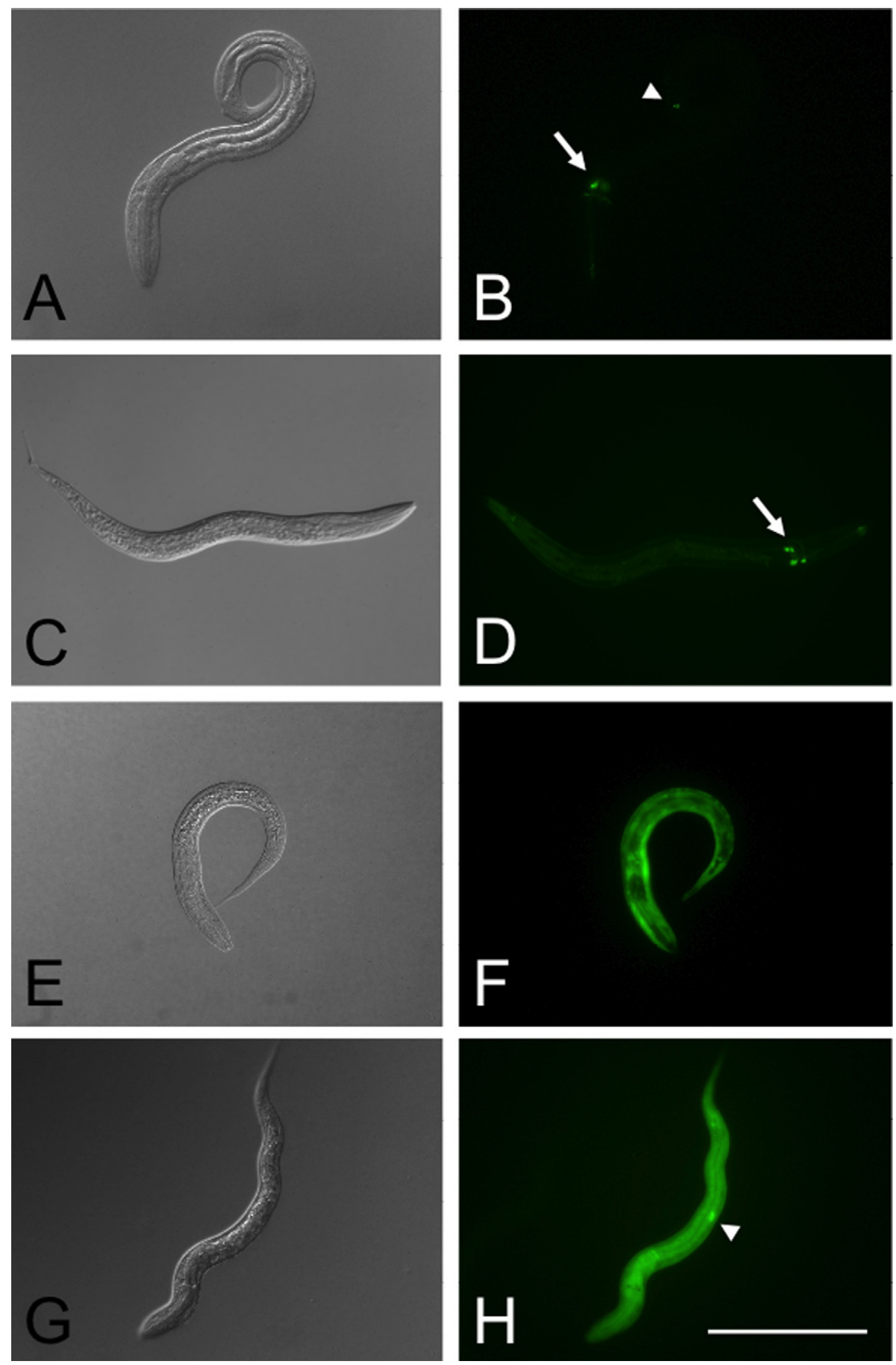

Fig. 3. Neuron-specific and ubiquitous expression of GFP reporter constructs containing regulatory sequences from Strongyloides stercoralis in transgenic first-stage larvae of Strongyloides ratti and S. stercoralis. In all constructs the gfp coding sequence is flanked by the Ss-era-1 $3^{\prime}$ UTR and the putative promoter from one of the following genes: Ss-gpa-3 (plasmid pAJ09) or Ss-rps-21 (plasmid pAJ20). (A, B) Expression of plasmid pAJ09 in S. stercoralis. (C, D) Expression of pAJ09 in S. ratti. Note expression in cell bodies of amphidial neurons in both parasites (arrows). S. stercoralis also shows expression of this construct in a phasmidial neuron (arrow head). (E, F) Expression of construct pAJ20 in S. stercoralis. (G, H) Expression of pAJ20 in S. ratti. Note ubiquitous expression of this construct in both parasites. S. ratti shows an intense locus of expression in the genital rudiment (arrow head). Scale bar $=200 \mu \mathrm{m}$. 
were screened for GFP fluorescence as first-stage larvae, and digital images were captured.

Expression of all S. stercoralis-based reporter transgene constructs was observed in a proportion of F1 progeny of microinjected free-living $S$. ratti females (Table 1 ). Free-living females of $S$. ratti tolerated microinjection somewhat less well than those of S. stercoralis, and resulting mortality among these worms is reflected in a comparatively lower yield of total F1 larvae per microinjected female in this initial trial (Table 1). In general, the anatomical patterns of expression for a given reporter construct in $S$. ratti closely resembled the pattern observed here and previously for the same construct in S. stercoralis (Fig. 2) [8,9]. The same intestinal cellspecific pattern of GFP expression under the Ss-era-1 promoter in plasmid pPV230.13 was observed in both S. stercoralis [8] (Fig. 2A and B) and in S. ratti larvae (Fig. 2C and D). Similarly, the S. stercoralis actin promoter in plasmid pAJ08 drove GFP expression in the same body wall-specific pattern in S. ratti larvae (Fig. $2 \mathrm{G}$ and $\mathrm{H}$ ) as it did in $S$. stercoralis larvae observed here (Fig. 2E and F) and previously [9]. The Ss-gpa-3 promoter in plasmid pAJ20 drove GFP expression in amphidial neurons of transgenic S. stercoralis (Fig. 3A and B) and S. ratti (Fig. 3C and D) larvae. Expression of GFP from plasmid pAJ09 was also seen in phasmidial neurons of some $S$. stercoralis larvae [9] (Fig. 3B) but not in the transgenic S. ratti larvae observed in this study (Fig. 3D). This character is variable in S. stercoralis, and not all larvae expressing the transgene in the amphidial neurons do so in phasmidial neurons [9]. Finally, the same ubiquitous pattern of GFP expression under the $S$. stercoralis Ss-rps-21 promoter in plasmid pAJ20 was seen in transgenic S. stercoralis (Fig. 3E and F) [9] and S. ratti (Fig. $3 \mathrm{G}$ and $\mathrm{H}$ ). An intense locus of expression in the genital rudiment of $S$. ratti L1 transformed with plasmid pAJ20 (Fig. $3 \mathrm{H}$ ) has also been reported for S. stercoralis [9].

Thus, we have achieved transgenesis in $S$. ratti using the same method of gonadal microinjection that we adapted from C. elegans methodology for S. stercoralis [7]. We have also found that the functions of gene regulatory sequences from $S$. stercoralis, comprising four putative promoters and a single multi-functional $3^{\prime}$ UTR, are sufficiently conserved in $S$. ratti to give virtually identical anatomical and cellular patterns of GFP reporter expression in the 2 parasites. The frequencies of transformation among F1 progeny of microinjected females were higher in $S$. stercoralis than in $S$. ratti for all constructs tested. For three of the four transgene constructs tested (pAJ08, pPV230.13 and pAJ09) this disparity can be explained by the facts that only one gonadal arm was injected in S. ratti, and observed frequencies in that parasite are roughly half those observed in S. stercoralis (Table 1 ) where both arms were injected. The larger disparity observed in the case of pAJ20 may reflect the heterologous nature of this $S$. stercoralis-based construct in $S$. ratti, notwithstanding conservation of the anatomical expression pattern, and might be overcome by the use of a construct with homologous regulatory elements. The robust nature of the EST database for S. ratti [31] and the imminent completion of a full draft genome for this parasite [32] will greatly facilitate the creation of such homologous constructs. In general we found $S$. ratti to be somewhat less tolerant of microinjection than S. stercoralis and this was reflected in a higher mortality among parental females in the first $24 \mathrm{~h}$ following DNA transfer and a consequently lower total of F1 progeny per female microinjected in $S$. ratti than in S. stercoralis. Nevertheless, we believe that when we attempt to derive stable lines of transgenic Strongyloides spp. by host passage, these disparities will be more than offset by the 8- to 15 -fold higher infection efficiency seen in the $S$. ratti-rat system compared to $S$. stercoralis-gerbil system. As discussed above, the ability of 50-100\% of inoculated $S$. ratti $\mathrm{L} 3 \mathrm{i}$ to establish as reproductively competent parasitic females in the rat $[27,28]$ will greatly increase the probability of capturing the expected $1-10 \%$ of $F 1$ transformants that carry transgene sequences in their germlines and thus constitute founders of transgenic lines. Transgenesis in $S$. ratti is a significant development given the relatively highly developed nature of genetics, and developmental and evolutionary biology in this parasite. These areas are accompanied by increasingly robust genomic and transcriptomic data sets, and transgenesis in a tractable parasite like $S$. ratti will be an asset in assigning function to genes and transcripts that are parasite specific and therefore encode potential targets for drug or vaccine intervention.

\section{Acknowledgments}

We thank Euihye Jung and Beth Maguire for technical assistance. This work was supported by National Institutes of Health grants AI82548 to James B. Lok and Edward J. Pearce, by AI50668 and AI22662 to James B. Lok and by RR02512 to M.L. Haskins.

\section{References}

[1] Stinchcomb DT, Shaw JE, Carr SH, Hirsh D. Extrachromosomal DNA transformation of Caenorhabditis elegans. Mol Cell Biol 1985;5:3484-96.

[2] Fire A. Integrative transformation of Caenorhabditis elegans. EMBO J 1986;5:2673-80.

[3] Fire A, Kondo K, Waterston R. Vectors for low copy transformation of C. elegans. Nucleic Acids Res 1990;18:4269-70.

[4] Blaxter ML, DeLey P, Garey JR, et al. A molecular evolutionary framework for the phylum Nematoda. Nature 1998;392:71-5.

[5] Dorris M, Viney ME, Blaxter ML. Molecular phylogenetic analysis of the genus Strongyloides and related nematodes. Int J Parasitol 2002;32:1507-17.

[6] Viney ME, Lok JB. Strongyloides spp. In: The C. elegans Research Community, editor. WormBook. Wormbook; 2007. doi:10.1895/wormbook.1.141.1, http://www.wormbook.org.

[7] Lok JB, Massey Jr HC. Transgene expression in Strongyloides stercoralis following gonadal microinjection of DNA constructs. Mol Biochem Parasitol 2002;119:279-84.

[8] Li X, Massey HC, Nolan TJ, et al. Successful transgenesis of the parasitic nematode Strongyloides stercoralis requires endogenous non-coding contro elements. Int J Parasitol 2006;36:671-9.

[9] Junio AB, Li X, Massey Jr HC, et al. Strongyloides stercoralis: cell- and tissue-specific transgene expression and co-transformation with vector constructs incorporating a common multifunctional 3' UTR. Exp Parasitol 2008; 118:253-65.

[10] Grant WN, Stasiuk S, Newton-Howes J, et al. Parastrongyloides trichosuri, a nematode parasite of mammals that is uniquely suited to genetic analysis. Int J Parasitol 2006;36:453-66.

11] Grant WN, Skinner SJM, Howes JN, et al. Heritable transgenesis of Parastrongyloides trichosuri: a nematode parasite of mammals. Int J Parasitol 2006;36:475-83.

[12] Nolan TJ, Zhu X, Ketschek A, et al. The sugar glider (Petaurus breviceps): a laboratory host for the nematode Parastrongyloides trichosuri. J Parasitol 2007;93:1084-9.

[13] Hirata T, Uchima N, Kishimoto K, et al. Impairment of host immune response against Strongyloides stercoralis by human T cell lymphotropic virus type 1 infection. Am J Trop Med Hyg 2006;74:246-9.

[14] Carvalho EM, Da Fonseca Porto A. Epidemiological and clinical interaction between HTLV-1 and Strongyloides stercoralis. Parasite Immunol 2004;26:487-97.

[15] Mitsunaga M, Miyauchi N, Akiyama Y, Saima S. A case of strongyloidiasis hyperinfection during oral corticosteroid therapy associated with a nephrotic patient infected with HTLV-1. Nippon Ronen Igakkai Zasshi 2003;40: 397-401.

[16] Schaeffer MW, Buell JF, Gupta M, Conway GD, Akhter SA, Wagoner LE. Strongyloides hyperinfection syndrome after heart transplantation: case report and review of the literature. J Heart Lung Transplant 2004;23:905-11.

[17] Nolan TJ, Megyeri Z, Bhopale VM, Schad GA. Strongyloides stercoralis: the first rodent model for uncomplicated and hyperinfective strongyloidiasis, the Mongolian gerbil (Meriones unguiculatus). J Infect Dis 1993;168:1479-84.

[18] Mello C, Fire A. DNA transformation. Methods Cell Biol 1995;48:451-82.

[19] Wilkes CP, Thompson FJ, Gardner MP, Paterson S, Viney ME. The effect of the host immune response on the parasitic nematode Strongyloides ratti. Parasitology 2004;128:661-9.

[20] Viney ME. Developmental switching in the parasitic nematode Strongyloides ratti. Proc R Soc Lond B Biol Sci 1996;263:201-8.

[21] Viney ME, Matthews BE, Walliker D. On the biological and biochemical nature of cloned populations of Strongyloides ratti. J Helminthol 1992;66:45-52.

[22] Gardner MP, Gems D, Viney ME. Extraordinary plasticity in aging in Strongyloides ratti implies a gene-regulatory mechanism of lifespan evolution. Aging Cell 2006;5:315-23.

[23] Thompson FJ, Barker GL, Nolan T, Gems D, Viney ME. Transcript profiles of longand short-lived adults implicate protein synthesis in evolved differences in ageing in the nematode Strongyloides ratti. Mech Ageing Dev 2009;130:167-72. 
[24] Viney ME, Green LD, Brooks JA, Grant WN. Chemical mutagenesis of the parasitic nematode Strongyloides ratti to isolate ivermectin resistant mutants. Int J Parasitol 2002;32:1677-82.

[25] Evans H, Mello LV, Fang Y, et al. Microarray analysis of gender- and parasite-specific gene transcription in Strongyloides ratti. Int J Parasitol 2008;38:1329-41.

[26] Thompson FJ, Barker GL, Hughes L, Viney ME. Genes important in the parasitic life of the nematode Strongyloides ratti. Mol Biochem Parasitol 2008;158:112-9.

[27] Tindall NR, Wilson PA. An extended proof of migration routes of immature parasites inside hosts: pathways of Nippostrongylus brasiliensis and Strongyloides ratti in the rat are mutually exclusive. Parasitology 1990;100(Pt 2):281-8.

[28] Viney ME. Exploiting the life cycle of Strongyloides ratti. Parasitol Today 1999;15:231-5.
[29] Lok JB. Strongyloides stercoralis: a model for translational research on parasitic nematode biology. In: The C. elegans Research Community, editor. WormBook. Wormbook; 2006. doi:10.1895/wormbook1.134.1, http://www.wormbook.org.

[30] Viney ME, Matthews BE, Walliker D. Mating in the nematode parasite Strongyloides ratti: proof of genetic exchange. Proc R Soc Lond B Biol Sci 1993;254:213-9.

[31] O'Meara H, Barber R, Mello LV, Sangaralingam A, Viney ME, Paterson S. Response of the Strongyloides ratti transcriptome to host immunological environment. Int J Parasitol 2010;40:1609-17.

[32] Nemetschke L, Eberhardt AG, Viney ME, Streit A. A genetic map of the animal-parasitic nematode Strongyloides ratti. Mol Biochem Parasitol 2010;169:124-7. 